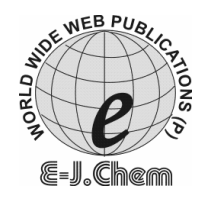

http://www.e-journals.net
ISSN: 0973-4945; CODEN ECJHAO

E-Journal of Chemistry

2009, 6(1), 133-137

\title{
Effect of Position and Number of Hydroxyl Groups on the Oscillatory Behaviour of Isomers of Hydroxybenzoic Acid
}

\author{
MASOOD A NATH* NADEEM B. GANAIE, \\ R. P. RASTOGI and G. M. PEERZADA
}

\author{
Department of Chemistry, \\ University of Kashmir, Srinagar-190006, (J \& K), India. \\ nath_masood@yahoo.co.in
}

Received 1 April 2008; Revised 12 June 2008; Accepted 10 August 2008

\begin{abstract}
In the present communication, the effect of isomers of hydroxybenzoic acids with respect to their oscillatory behaviour as organic substrates with inorganic bromate and manganese(II) ion as catalyst in aqueous acid medium $\left(1.0 \mathrm{M} \mathrm{H}_{2} \mathrm{SO}_{4}\right)$ have been studied. The number and the relative position of hydroxyl groups (-OH) in the aromatic ring is found to influence the oscillatory behaviour. Besides, the role of bromination reaction and the formation of corresponding bromoderivative is found to be an important step. The experimental findings are within the purview of Field, Koros and Noyes (FKN) mechanism.
\end{abstract}

Keywords: Belousov-Zhabotinsky reaction (BZ), FKN mechanism, Hydroxybenzoic acid, Inorganic bromate, Manganese(II) ion.

\section{Introduction}

Belousov-Zhabotinsky reaction $(\mathrm{BZ})^{1-3}$ is one of the most studied reaction which shows oscillatory behaviour. A large number of aromatic compounds such as polyphenols and aniline derivatives are found to exhibit oscillatory behaviour in acidic bromate either in presence or else in absence of metal ion catalyst. Different organic substrates have been used as BZ oscillators either as single or mixed substrates ${ }^{4-6}$. Glycolytic oscillations ${ }^{7-8}$ and peroxidase catalysed oxidation of nicotinamide adenosine dehydrogenase (NADH) have also generated considerable interest. The interest in such reactions is also sustained in view of their importance in cardiac and neuronal oscillations. The oscillatory behaviour of these reactions can be monitored in various ways, e.g. visually from sharp color changes, potentiometrically from potential changes, amperometrically from current changes, spectrophotometrically from changes in absorption, thermometrically or calorimetrically from changes in temperature ${ }^{9-11}, \mathrm{pH}$-metrically from change in $\mathrm{pH}$ etc. Recently, nuclear 
magnetic resonance $(\mathrm{NMR})^{12}$, magnetic resonance imaging $(\mathrm{MRI})^{13}$ and electron paramagnetic resonance (EPR $)^{14-16}$ studies of oscillating chemical reactions have been made. Obviously all methods are not applicable to all reactions.

The detailed mechanism of oscillating chemical reactions is proposed by Field, Koros and Noyes $(\mathrm{FKN})^{17}$ in 1972 and accepted universally and the same was confirmed by Edelson et al $^{18}$ through computer simulations. According to this mechanism, there are reduced as well as oxidized states, depending on bromide ion concentration. Two types of reactions control the oscillations;

1. When $\left[\mathrm{Br}^{-}\right]$exceeds the critical limit $\left[\mathrm{Br}^{-}\right]_{\mathrm{cr}}$

$$
\begin{aligned}
& \mathrm{BrO}_{3}^{-}+\mathrm{Br}^{-}+2 \mathrm{H}^{+} \\
& \mathrm{HBrO}_{2}+\mathrm{Br}^{-}+\mathrm{H}^{+} \leftrightarrow \mathrm{HBrO}_{2}+\mathrm{HOBr} \\
& \mathrm{HOBr}+\mathrm{Br}^{-}+\mathrm{H}^{+} \leftrightarrow \mathrm{HOBr}_{2}+\mathrm{Br}_{2}+\mathrm{H}_{2} \mathrm{O}
\end{aligned}
$$

It is important to note that bromide ion is released through the following step,

$$
\mathrm{Mn}^{3+}+\text { Bromoderivative } \rightarrow \mathrm{Mn}^{2+}+\mathrm{Br}^{-}
$$

2. When $\left[\mathrm{Br}^{-}\right]$is below the critical limit $\left[\mathrm{Br}^{-}\right]_{\mathrm{cr}}$

$$
\begin{aligned}
& \mathrm{BrO}_{3}^{-}+\mathrm{HBrO}_{2}+\mathrm{H}^{+} \leftrightarrow 2 \mathrm{BrO}_{2}{ }^{-}+\mathrm{H}_{2} \mathrm{O} \\
& \mathrm{Mn}^{2+}+\mathrm{BrO}_{2}+\mathrm{H}^{+} \leftrightarrow \mathrm{Mn}^{3+}+\mathrm{HBrO}_{2} \\
& 2 \mathrm{HBrO}_{2} \leftrightarrow \mathrm{HOBr}+\mathrm{BrO}_{3}^{-}+\mathrm{H}^{+}
\end{aligned}
$$

The steps (5) and (6) represent the autocatalysis of $\mathrm{HBrO}_{2}$ obtained by multiplying step (5) by 2 and then adding them.

The hard core of control mechanism of the oscillation is either a positive feedback (autocatalysis) or else a negative feedback (inhibitory reaction) as shown under:-

$$
\begin{aligned}
& \mathrm{BrO}_{3}{ }^{-}+\mathrm{HBrO}_{2}+3 \mathrm{H}^{+}+2 \mathrm{Ce}^{3+} \rightarrow 2 \mathrm{HBrO}_{2}+2 \mathrm{Ce}^{4+}+\mathrm{H}_{2} \mathrm{O} \\
& \text { (positive feedback) } \\
& \mathrm{HBrO}_{2}+\mathrm{Br}^{-}+\mathrm{H}^{+} \rightarrow 2 \mathrm{HOBr} \\
& \text { (negative feedback) }
\end{aligned}
$$

Besides, there are other steps in the mechanism involving $\mathrm{HBrO}_{2}, \mathrm{BrO}_{2}{ }^{\cdot}, \mathrm{HOBr}, \mathrm{Br}^{-}$etc.

In view of the fact that the rate constant of the reaction in the negative feedback is of much smaller magnitude, it is expected that inhibitory reaction is most likely to primarily influence the oscillatory characteristics such as induction time, time period and life time. In the present communication, effect of change of substrate viz., isomers of hydroxybenzoic acid having different position and number of $-\mathrm{OH}$ groups have been studied in depth. The number and position of $-\mathrm{OH}$ groups influence the feasibility of bromination.

\section{Experimental}

The chemicals used are para-hydroxybenzoic ( $p \mathrm{HBA}$ ) acid (Himedia), meta-hydroxybenzoic acid ( $m$ HBA) (Himedia), ortho-hydroxybenzoic acid (oHBA) (Qualigens), 3,4dihydroxybenzoic acid (3,4DHBA) (Fluka), 3,5-dihydroxybenzoic acid (3,5DHBA) 2,4dihydroxybenzoic acid (2,4DHBA) (Himedia), 3,4,5-trihydroxybenzoic acid (gallic acid) (SRL), polymeric 3,4,5 THBA (tannic acid) (Excel-R), manganous sulphate monohydrate $(\mathrm{BDH})$ and potassium bromate (Merck). All the reagents used were analytical grade (AR) and the desired solutions were prepared in $1.0 \mathrm{M}$ sulphuric acid (Merck) of $98 \%$ purity.

The Ion-Meter (Elico-126) having $\mathrm{pH}$ as well as $\mathrm{mV}$ option was setup in order to record change in $\mathrm{mV}$ versus time for the reaction systems. The reaction system comprising of any one of the aforesaid organic substrates, potassium bromate and $\mathrm{Mn}$ (II) solution were taken 
in one of the half cells into which a platinum electrode was dipped as the indicator electrode, whereas calomel electrode was taken as the reference electrode (SCE) in another half cell, containing $2.5 \times 10^{-4} \mathrm{M}$ solutions of potassium chloride. The two half cells were connected through a salt bridge and kept immersed in a high precision water bath (Jindal-S. M. Scientific instruments) set up at desired temperature $\left(35^{0} \pm 0.2^{0} \mathrm{C}\right)$. The potential change in $\mathrm{mV}$ was recorded after every ten or five seconds whichever was easy to monitor.

\section{Results and Discussion}

The oscillatory characteristics like induction time $\left(t_{i}\right)$ in minutes, time period $\left(t_{p}\right)$ in minutes and the number of oscillations were obtained by plotting observed potential changes in $\mathrm{mV}$ versus time (Figure 1) and the data is depicted in Table 1. Results recorded in Table 1 show that in the monohydroxybenzoic acids, $p$-HBA is more reactive than $o$-HBA and $m$-HBA. In view of this and from the depicted structures- I, II, III of these isomers, it becomes apparent that bromination reaction is more favourable in $p$-HBA owing to the fact that bromine occupies the position ortho to $-\mathrm{OH}$ group and meta to $-\mathrm{COOH}$ group. Keeping in view that $-\mathrm{OH}$ is $o, p$ directing and $-\mathrm{COOH}$ group is meta directing. This can also be observed by their oscillatory characteristics as shown in Figure 1.

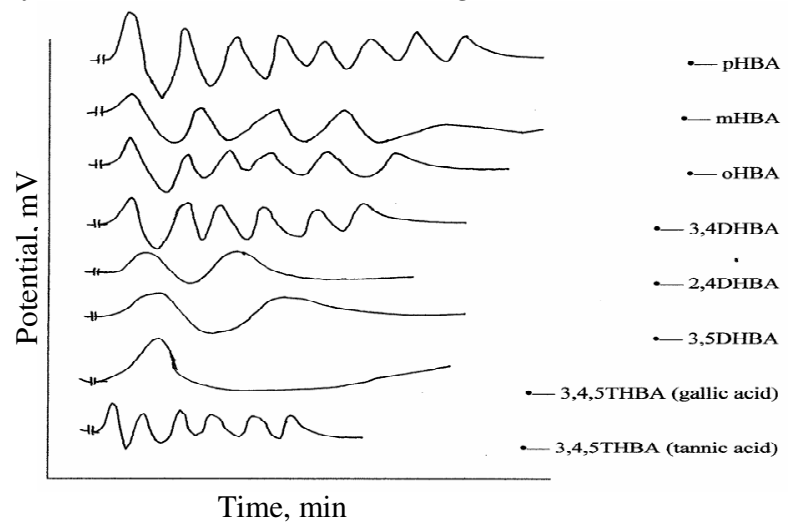

Figure 1. Potential time plots of the systems comprising of various isomers of hydroxybenzoic acid $(0.0070 \mathrm{M})$ each; $\left[\mathrm{BrO}_{3}{ }^{-}\right]=0.0750 \mathrm{M} ;\left[\mathrm{Mn}^{2+}\right]=0.0080 \mathrm{M}$; in $1.0 \mathrm{M}$ $\mathrm{H}_{2} \mathrm{SO}_{4}$ at $35^{\circ} . \pm 0.2^{\circ} \mathrm{C}$.

Table 1. Effect of hydroxyl groups on the oscillatory parameters of the isomers of hydroxybenzoic acid in the system containing $[o \mathrm{HBA}]=[m \mathrm{HBA}]=[p \mathrm{HBA}]=[3,4-\mathrm{DHBA}]$ $=[3,4,5-\mathrm{THBA}]=0.0070 \mathrm{M} ;\left[\mathrm{BrO}_{3}^{-}\right]=0.0750 \mathrm{M} ;\left[\mathrm{Mn}^{2+}\right]=0.0080 \mathrm{M} ;\left[\mathrm{H}_{2} \mathrm{SO}_{4}\right]=1.0 \mathrm{M}$ and Temperature $=35^{\circ} . \pm 0.2^{\circ} \mathrm{C}$.

\begin{tabular}{cccc}
\hline Organic substrate $(\mathrm{s})$ & $\mathrm{t}_{\mathrm{i}}$, min. & $\mathrm{t}_{\mathrm{p}}$ min. & No. of oscillations \\
\hline 4-HBA $(p$-HBA) & 1.33 & 2.70 & 12 \\
3-HBA ( $m$-HBA) & 2.33 & 9.66 & 08 \\
2-HBA $(o$-HBA) & 1.66 & 5.72 & 14 \\
3,4-DHBA & 1.50 & 4.11 & 10 \\
3,5-DHBA & 2.13 & $*$ & 02 \\
2,4-DHBA & 2.00 & 5.20 & 03 \\
3,4,5-THBA (gallic acid) & $*$ & $*$ & 01 \\
3,4,5-THBA (tannic acid) & 2.00 & 1.50 & 10 \\
\hline
\end{tabular}

* the value being large is difficult to calculate. 


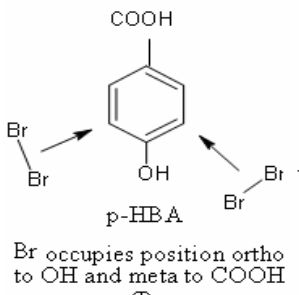

(I)

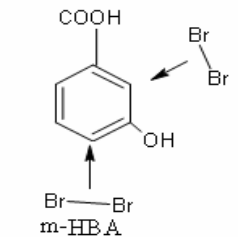

Br can't occupy position between the two groups

(II)

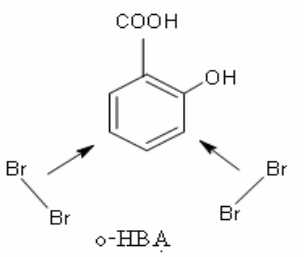

Intramolecular $\mathrm{H}$-bonding

(III)

Hence the reactivity of monohydroxybenzoic acids follows the order.

$$
p \text {-HBA }>o \text {-HBA }>m \text {-HBA }
$$

It is important to note that ortho isomer should have been more reactive, but because of intramolecular hydrogen bonding in the molecule, the problem of solubility in aqueous acid medium arises. However, on slight heating its solubility increases and hence can work as a chemical oscillator. Further, the different behaviour is obtained by changing the catalyst.

In case of isomers of dihydroxybenzoic acids, 3, 4-DHBA is more reactive than 3, 5DHBA and 2, 4-DHBA. The reason is again same, i.e., 3, 4-DHBA is easily brominated than other isomers as is evident from the following structures.

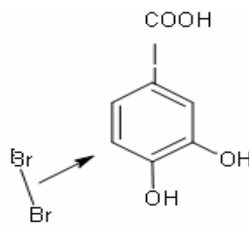

3, 4-DHBA

Bromination favourable

(TV)

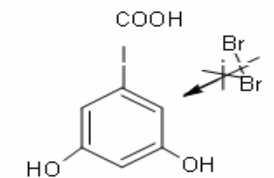

3, 5-DHBA

(V)

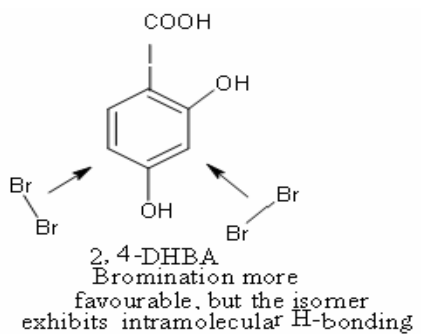

(vI)

Thus the reactivity of dihydroxybenzoic acids decrease in the following order:-

$$
\text { 3,4-DHBA > 2,4-DHBA > 3,5-DHBA }
$$

Trihydroxybenzoic acids like gallic acid (structure VII) shows less oscillatory behaviour than mono and dihydroxybenzoic acids. This is because bromination reaction is very difficult between $-\mathrm{COOH}$ and $-\mathrm{OH}$ group. Also, as the molecule is sterically hindered, the lone pair of electrons on bromine repel with these groups thereby making the bromination reaction very slow. Bromination is more unfavourable.<smiles>CC(C)(C)C(C)(C)C</smiles>

\section{3,4,5-THBA (Gallic acid)}

However, Rastogi and coworkers observed oscillation of gallic acid alone at $50^{\circ} \mathrm{C}$. Gallic acid shows better oscillations in presence of $\mathrm{Ce}(\mathrm{IV})$ or $\mathrm{Fe}$ (II) and in mixed substrate systems. However, tannic acid, a resinous polymeric trihydroxybenzoic acid shows excellent oscillation of high frequency due to the presence of large number of free hydroxyl groups which activate the position for bromination to occur. 
The comparative study of these isomers show that with the increase in the number of hydroxyl groups the rate of bromination decreases, hence the oscillatory characteristics become less prominent. This is attributed to the fact that di and trihydroxybenzoic acids form quinones and the oscillations cease if the product of oxidation is stable quinone ${ }^{20}$. Since gallic acid forms more stable quinone than 3,4-DHBA and no quinone is possible for monohydroxybenzoic acids such as $p$-HBA. Thus the overall reactivity on the basis of number of hydroxyl groups in different isomers of hydroxybenzoic acid follows the order

\section{Conclusion}

$$
p \text {-HBA }>3,4 \text {-DHBA }>3,4,5 \text {-THBA }
$$

- On the basis of number and position of -OH groups, three types of isomers of hydroxybenzoic acid have been studied as oscillators in BZ reaction.

- In monohydroxybenzoic acids, parahydroxybenzoic acid is more reactive.

- In dihydroxybenzoic acids, 3,4 dihydroxybenzoic acid is more reactive.

- Amongst the three types of isomers of hydroxybenzoic acid studied, trihydroxy isomers are least reactive and monohydroxybenzoic acids ( $p$-HBA) are most reactive oscillators in BZ reaction.

\section{References}

1. Field R J and Burger M, Oscillations and Travelling Waves in Chemical Systems; Wiley Interscience: New York, 1985.

2. Belousov B P, Collection of Abstracts on Radiation Medicine, Medgiz: Moscow, $1959,145$.

3. Zhabotinskii A M, Biofizika, 1964, 9, 306.

4. $\quad$ Dutt A K and Banerjee R S, Chem Phys Lett., 1983, 99, 186.

5. Lalitha P V and Ramaswamy R React, Kinet Catal Lett., 1992, 47, 133.

6. Rastogi R P and Misra G P, Indian J Chem. Soc., 1990, 29(A), 1205.

7. Goldbeter A and Caplan R, Annu Rev Biophys Bioeng., 1976, 5, 449.

8. Goldbeter A, Biochemical Oscillations and Cellular Rhythms; Cambridge Univ Press., 1996.

9. Mukherjee K, Moulik S P and Mukherjee D C, Int J Chem Kinet., 1995, 27, 561.

10. Nagy G, Koros E and Lamprecht I, J Thermal Anal Calorim., 1999, 57, 209.

11. Mukherjee K, Basu S N, Mukherjee D C and Moulik S P, J Phys Chem., 2001, 215, 575.

12. Hansen E W and Ruoff P, J Phys Chem., 1989, 93, 2696.

13. Balcom B J, Carpentor T A and Hall L D, Macromolecules, 1992, 25, 6818.

14. Lalitha P V, Ramaswamy R, Ramakrishnan G and Rao P S, J Phys Chem.,1992, 96, 7679.

15. Lalitha P V, Rao P S and Ramaswamy R, Curr Sci., 1991, 61, 352.

16. Forsterling H D and Stuk L, J Phys Chem., 1991, 95, 7320.

17. Field R J, Koros E and Noyes R M, J Am Chem Soc., 1972, 94, 1394.

18. Edelson D, Field R J and Noyes R M, Int J Chem Kinet., 1975, 7, 417.

19. Rastogi R P and Misra G P, J Indian Chem Soc., 1990, 29(A), 1205.

20. Orban M and Koros E, J Phys Chem., 1978, 82, 14. 


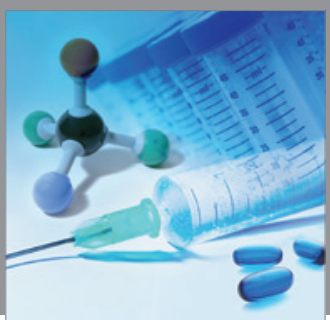

International Journal of

Medicinal Chemistry

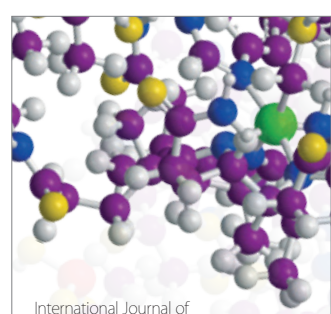

Carbohydrate Chemistry

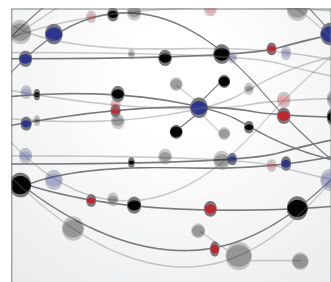

The Scientific World Journal
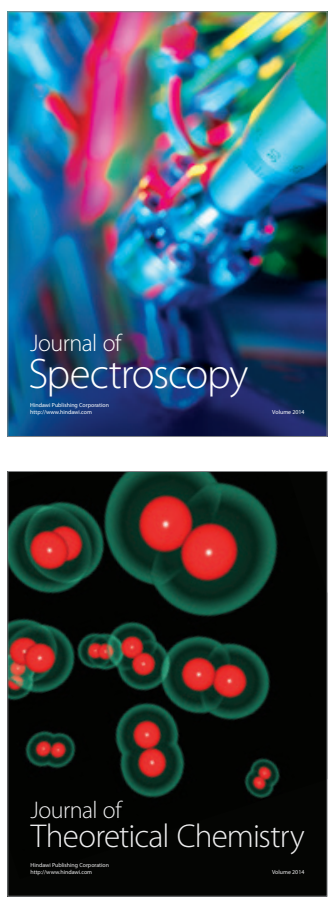
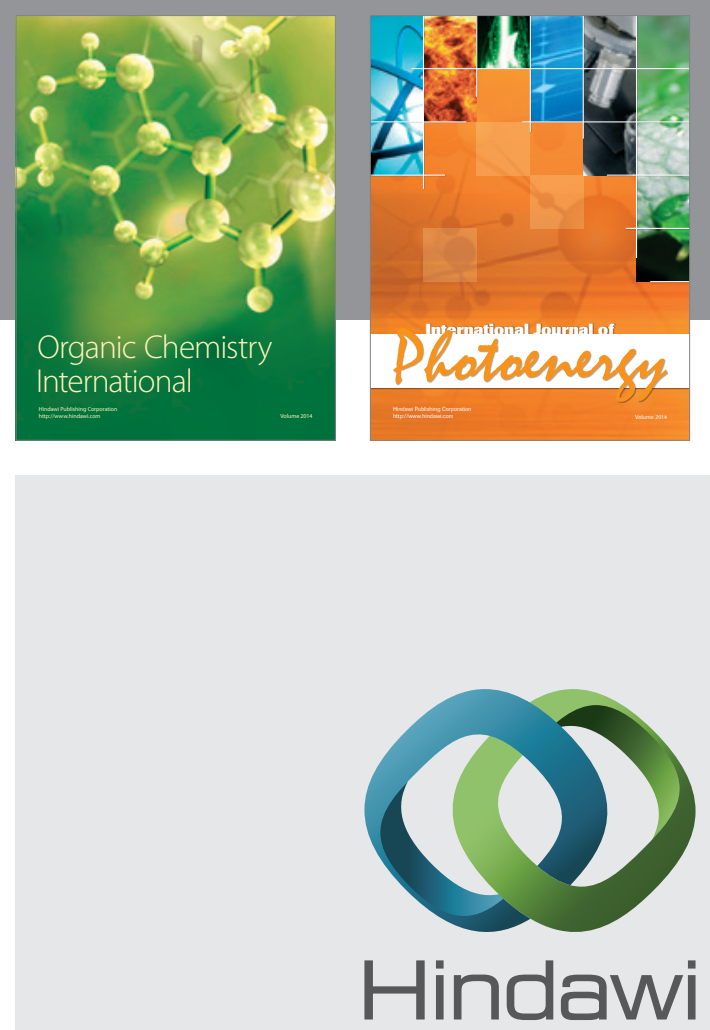

Submit your manuscripts at

http://www.hindawi.com
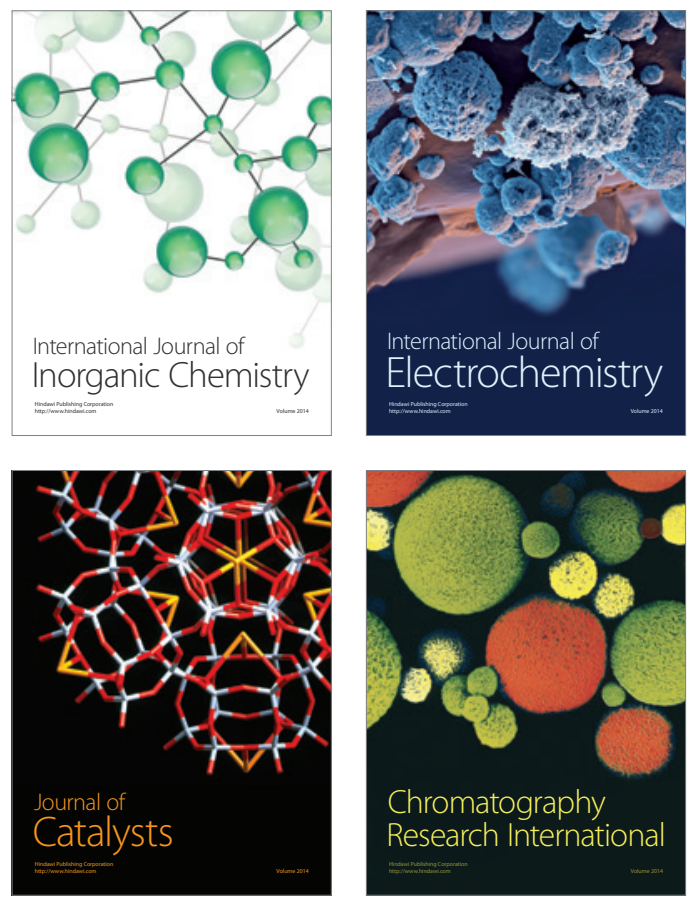
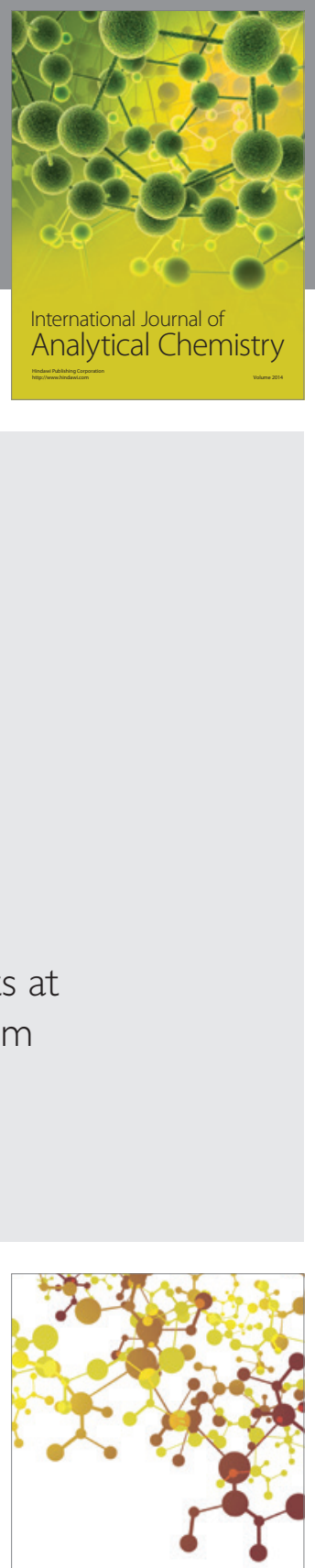

Journal of

Applied Chemistry
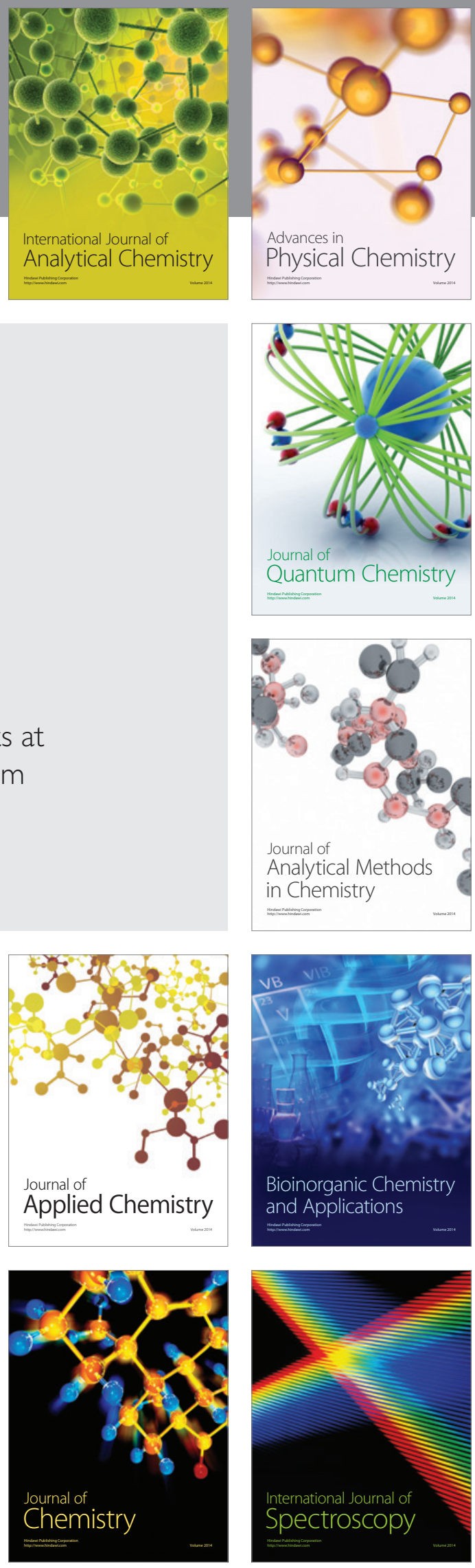